\title{
“ROSA DE OURO NUNCA FOI DE BRINCADEIRA" A PRESENÇA DA ARTE ERUDITA NO CARNAVAL DE ROSA MAGALHÃES
}

\author{
Dulce Regina Baggio Osinski (UFPR)
}

Gustavo Krelling (UFPR)

Os desfiles da carnavalesca Rosa Magalhães são o objeto de análise desta pesquisa, que investiga as referências à arte erudita presentes no trabalho da artista, inserido em uma festa popular, e como essas referências podem ser percebidas como processo de hibridação e circularidade.

ROSA MAGALHÃES, CIRCULARIDADE, HIBRIDAÇÃO, ERUDITO, POPULAR. 
Este artigo discute a presença de referências à arte erudita no trabalho da carnavalesca Rosa Magalhães, enfatizando o desfile realizado pela Escola de Samba Imperatriz Leopoldinense em 2004; também aponta como essas referências contribuem para que ocorram os processos de circularidade, de acordo com Ginzburg (1987), e de hibridação, conforme conceito elaborado por Canclini (2000), entre a cultura popular e a erudita.

Ginzburg (1987) define o relacionamento circular como feito de influências recíprocas, que se pode mover de baixo (cultura popular/subalterna) para cima (cultura erudita/hegemônica), bem como de cima para baixo. Segundo o autor, uma cultura pode ser integrada à outra. Por sua vez, a hibridação, definida por Canclini (2000), se refere às relações interculturais e consiste no encontro entre o culto, o popular e o massivo - meios de comunicação de massa e cultura de massa -, um trabalho transdisciplinar para a meIhor comunicação entre camadas sociais. A hibridação cria um processo de comunicação horizontal que não reconhece relações hierárquicas entre as referidas modalidades culturais. $\mathrm{O}$ autor também utiliza os termos sincretismo e mestiçagem para abordar essa relação entre culturas.

Observamos que a referência à arte erudita é uma constante nos desfiles realizados pela carnavalesca, porém a escolha do desfile do ano de 2004, com o enredo Breazail, se justifica pela grande presença de citações à arte erudita. $O$ erudito, nesta pesquisa, é representado pelas artes visuais enquanto campo institucionalizado e referendado por museus e galerias, bem como por teorias específicas, e representado por artistas reconhecidos por esse sistema. O popular aparece através da visualidade das escolas de samba do Grupo Especial do Rio de Janeiro.

Vale lembrar que, como carnavalesca, Rosa Magalhães assinou a concepção visual dos desfiles da Imperatriz Leopoldinense entre 1992 e 2009, e da União da Ilha do Governador em 2010, tendo anteriormente realizado trabalhos em outras escolas de samba. Atualmente é responsável pelo carnaval da Vila Isabel. Observamos que a arte erudita emerge no contexto popular de várias formas nessas ocasiões, exemplificando a materialização dos conceitos de circularidade e hibridação. Outro fator que justifica a escolha de Rosa Magalhães para esta reflexão está em sua formação de caráter eru-

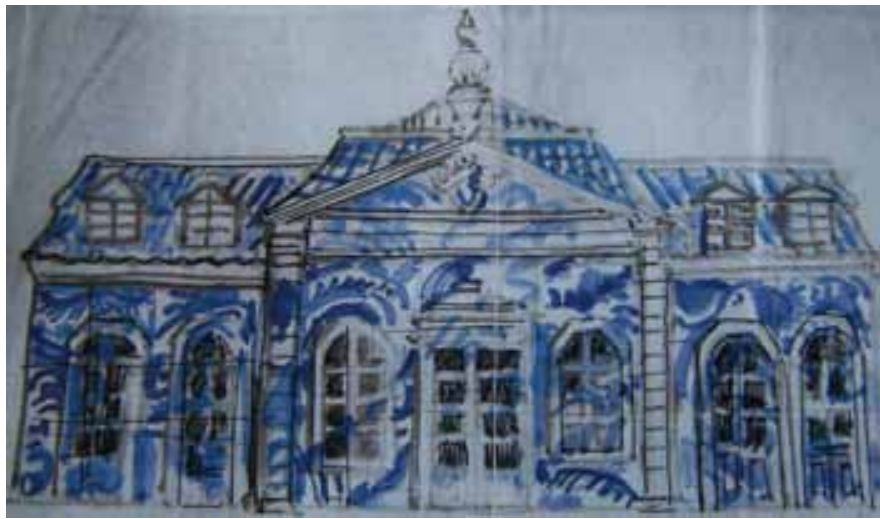

Figura 1: Desenho de Rosa MagaIhães para alegoria que representa a fuga de Dom Jõao VI para o Brasil; Carnaval 2008; guache sobre papel, 2007 Fonte: barracão da Imperatriz Leopoldinense, 2010. 
dito. Embora a artista seja bacharel em pintura e cenografia, sua trajetória profissional é marcada pela idealização e materialização de obra inserida numa festa popular. Com isso, ela estabelece dentro da cultura popular um diálogo não só com o público em geral, que aprecia os aspectos gerais de seus desfiles, mas também com uma faixa mais estrita da população, o público conhecedor de arte, muitas vezes representado pelos jurados que conferem notas à apresentação da escola. Não obstante, para o pesquisador de carnaval Felipe Ferreira (em entrevista concedida em 21.07.2010) em alguns casos nem os próprios jurados percebem as referências à arte erudita feitas por Rosa Magalhães.

Para a contextualização do presente artigo foram analisados todos os desfiles de Rosa Magalhães na Imperatriz Leopoldinense (1992-2009) e na União da Ilha do Governador (2010), além dos desfiles realizados pela carnavalesca na Escola de Samba Império Serrano (1982), na própria Imperatriz Leopoldinense em (1984), na Escola de Samba Estácio de Sá (1987, 1988 e 1989) e na Escola de Samba Acadêmicos do Salgueiro (1990 e 1991). Essa análise utilizou como fontes as gravações dos desfiles das escolas de samba do Grupo Especial do Rio de Janeiro, realizadas pela Rede Globo e pela Rede Manchete.

Também foram feitas algumas entrevistas que esclareceram a influência da arte erudita no trabalho de Rosa Magalhães: com o chefe de adereços da Imperatriz Leopoldinense, Sérgio Farias, que com ela trabalhou em muitos carnavais, e Felipe Ferreira, pesquisador de carnaval e da obra de Rosa Magalhães.

Para se ter ideia de alguns exemplos das referências feitas por Magalhães à arte erudita dentro de uma celebração popular, elencamos o desfile da Imperatriz Leopoldinense em 2008, com o enredo "João e Marias". A carnavalesca aponta nesse desfile as muitas marias presentes na vida de Dom João VI e relaciona esses personagens históricos com as marias e os joãos de nosso cotidiano, nomes dos mais populares em nosso país, fazendo também trocadilho com os personagens da cultura popular europeia. Em determinado ponto do desfile Rosa Magalhães representa a fuga de Dom João VI de Portugal. Essa alegoria (Figura 1) é inspirada nas obras da artista plástica brasileira contemporânea Adriana Varejão. Os azulejos do colonizador, representados na obra de Adriana Varejão (Figura 2), vão reforçar a ideia da vinda das tradições portuguesas para o Brasil, mas,

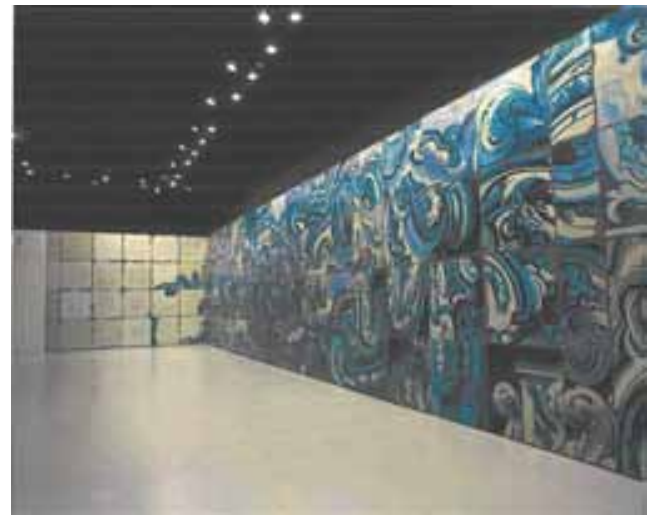

Figura 2: Adriana Varejão, Azulejões, 2001. Óleo sobre gesso e tela. Centro Cultural Banco do Brasil, Rio de Janeiro Fonte: Anthology of art, 2010. 
Figura 3: Rosa Magalhães, fantasia de espanhola para ala; Carnaval 2010; 2009 Fonte: Sidney Rezende, 2009.

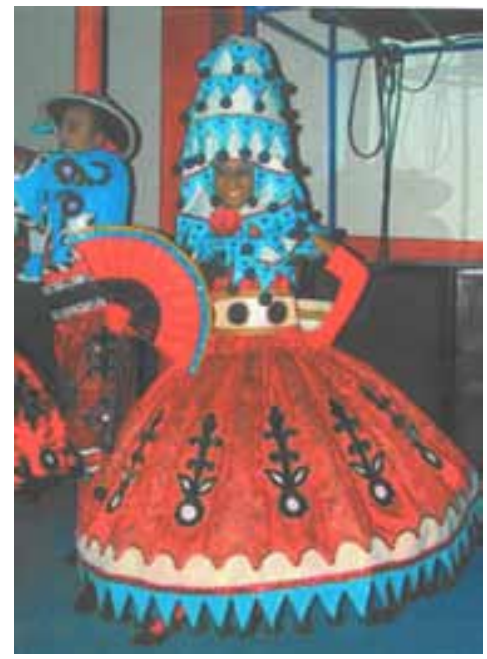

principalmente, constituem uma relação que Rosa Magalhães estabelece com a arte erudita. A arte contemporânea de Adriana Varejão, exposta geralmente em museus e galerias, vai ser vista em uma festa popular como o carnaval, caracterizando o processo de circularidade da cultura.

Também merece ser citada uma das fantasias de Rosa Magalhães no Carnaval de 2010 para o desfile da Escola de Samba União da Ilha do Governador (Figura 3), que tinha como enredo "Dom Quixote de La Mancha, o Cavaleiro dos Sonhos Impossíveis". A fantasia possui muitas semelhanças com os figurinos criados por Picasso para o balé La Tricorne (Figura 4), fato que evidencia a apropriação pertinente des-

1. Nesse enredo também havia citações a outro pintor espanhol, Francisco de Goya. se tipo de fonte pela artista. Ao mencionar Dom Quixote, personagem espanhol, ela busca no acervo de um pintor de igual nacionalidade e grande relevância referências para a visualidade de seu desfile. ${ }^{1}$

\section{A ROSA, O PANTAGRUEL E AS CULTURAS}

Era segunda-feira de carnaval, dia 19 de fevereiro de 2007 no Rio de Janeiro. 0 Grêmio Recreativo Escola de Samba Imperatriz Leopoldinense foi a quinta escola a desfilar na Avenida Marquês de Sapucaí. Rosa Magalhães (2006) apresentava seu $16^{\circ}$ desfile consecutivo como carnavalesca da agremiação e narrava, nesse ano, a história do bacalhau com o enredo "Teresinhaaa, uhuhuuu!!!! Vocês querem bacalhau?", referência ao apresentador Chacrinha, que jogava bacalhau em sua plateia. Chacrinha, no entendimento de Magalhães, tinha a consciência de que vivemos em um país plural e por isso trajava uma vestimenta que era uma mistura de Luís XV com elementos de consumo da classe média de então. Depois de apresentar Chacrinha, a história caminha para a mitologia nórdica, mostrando o início do mundo através da visão desses povos, pois os noruegueses, vikings, foram os primeiros exploradores e consumidores do bacalhau, de acordo 


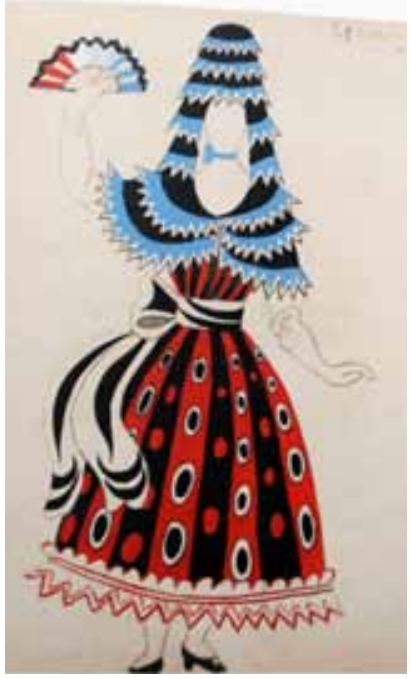

Figura 4: Pablo Ruiz Picasso, Vestidos de las bailarinas de la sevillana, 1919

Fonte: Parrondo, 2008.

com a carnavalesca. A narrativa de Magalhães prossegue para a descoberta do sal, que concedeu sabor e preservação ao alimento:

Foram os bascos que, durante a Idade Média, descobriram as propriedades do sal para a preservação dos alimentos. O sal, até então pouco usado e desconhecido por muitos povos, tornou-se essencial na culinária e era muito apreciado, pois além de preservar os alimentos para estocagem ainda realçava seu sabor. Era uma mercadoria tão apreciada quanto os temperos. Nos banquetes, o saleiro dava distinção aos convidados. Quanto mais próximo do saleiro, mais importante era o dignatário (MAGALHÃES, 2006).

Para ilustrar esse acontecimento, Rosa Magalhães apresenta uma alegoria com o título Celebração pantagruélica, um grande banquete. O referido carro alegórico possui dois níveis, que representam dois estamentos medievais. O superior é composto por grande mesa, sobre a qual a nobreza aprecia o peixe; trata-se do local do grande banquete pantagruélico. O nível inferior é uma enorme cozinha, local em que os servos preparam a comida.

O título do carro faz menção ao personagem Pantagruel, referência que é percebida pelo comentarista da Rede Globo na transmissão do desfile. Cléber Machado diz que "Pantagruel é um personagem que ficou conhecido (...) como um adjetivo para fortuna, boas mesas. É dos contos de Rabelais - escritor francês. A Celebração Pantagruélica, um Grande Banquete! Olha que mesa bem posta aí!". O comentarista se refere ao escritor da Idade Média Rabelais e lança ao público massivo - telespectador - a fonte erudita da carnavalesca, mediando a "deglutição" do erudito em uma manifestação popular por um meio de comunicação de massa (CANCLINI, 2000).

Rosa Magalhães representa o povo basco na Idade Média com uma citação a um personagem de Rabelais cujo nome, segundo Bakhtin (1993), está relacionado com a ali- 
mentação em suas obras - Pantagruel está sempre de boca aberta. Quando o personagem nasce, vem acompanhado, do ventre de sua mãe, por um comboio de bestas carregadas de sal e salgadinhos. 0 sal, na Idade Média, é o tema do carro proposto pela carnavalesca.

No livro de Rabelais, as imagens de banquete, isto é, do comer, do beber, da ingestão, estão diretamente ligadas às formas da festa popular (...) Não se trata de forma alguma do beber e comer cotidianos, que fazem parte da existência de todos os dias de indivíduos isolados. Trata-se do banquete que se desenrola na festa popular, no limite da boa mesa (BAKHTIN, 1993, p. 243).

Ao representar a fartura do sal nesse ambiente medieval, Rosa Magalhães propõe um diálogo com os banquetes de Rabelais, pois insere em uma festa popular - o desfile das escolas de samba do Rio de Janeiro - o banquete grotesco do referido autor. De acordo com Bakhtin (1993), o ato de comer e beber é um dos elementos mais importantes da vida no corpo grotesco, do degradante, do corpo baixo.

Temos, através do exemplo de Rabelais, a circularidade se concretizando pela apropriação de temas populares por um erudito. De acordo com Ferreira (1999, p. 32) "Rabelais é um caso de mediador entre duas culturas, visto que não inventou as histórias e personagens presentes em suas obras. Estes já existiam nos folhetos e na tradição oral francesa. Entretanto não se pode perder de vista que Rabelais era um erudito e que se utilizou deliberadamente da cultura popular".

O inverso acontece no trabalho de Rosa Magalhães, que irá, como veremos adiante, se apropriar da arte erudita em uma festa indicada pela maioria dos autores como de caráter popular.

\section{UMA ROSA QUE FALA: CARNAVAL E ARTE ERUDITA EM "BREAZAIL"}

A Imperatriz Leopoldinense tem como cores de sua bandeira o verde, o branco e o ouro. Em 2004, Rosa Magalhães "mudou" as cores da escola e desenvolveu seu enredo através da cor vermelha, contando a história do pau-brasil de maneira inusitada. $\mathrm{Na}$ sinopse do enredo a carnavalesca inicia a história indicando a receita de um bom vermelho para tingir a seda na Idade Média, um processo tido como mágico. Os alquimistas também são lembrados pela artista na obtenção da cor vermelha: "Dedicavam-se sobretudo na busca em transmutar outras substâncias em ouro e prata. Se não encontraram esta fórmula para os metais, descobriram outras, de valor talvez até maior" (MAGALHÃES, 2003). Após a referência aos químicos, a história caminha para o poder simbólico da cor: a fertilidade afasta maus espíritos, assegura a vitória no combate, é a cor dos reis. Rosa ainda cita a importância do vermelho na China e segue para o segredo da fabricação do vermelho, que era conhecido pelos fenícios, que o obtiveram com os povos celtas, através do dióxido de estanho: "os celtas chamavam o estanho de breazail, ou vermelhão. Existem muitas teorias, mas acredita-se que o termo brasil tenha origem celta."

Seguindo a história do vermelho no enredo, Rosa Magalhães apresenta Cristóvão Colombo que, ao chegar à América, escreve aos reis dizendo que a região do atual Brasil 
possuía grande quantidade de madeira tintorial. Dom Manuel então declara monopólio da Coroa a árvore mais tarde denominada pau-brasil.

Américo Vespúcio foi responsável pela fundação da primeira feitoria portuguesa na América, em Cabo Frio, no litoral fluminense, o primeiro entreposto que comercializava o pau-brasil. Vespúcio deixou 24 marinheiros encarregados da construção desse forte, prometeu que viria buscá-los, mas nunca mais voltou. As cartas que Vespúcio escrevia narrando suas viagens ao Novo Mundo eram sucesso na Europa. O filósofo inglês Thomas More encantou-se com as narrativas de Vespúcio e escreveu seu mais célebre livro, Utopia.

Um desses 24 marinheiros que ficaram em Cabo Frio, se torna o personagem chamado Rafael Hitlodeu, narrador de uma história que se tornaria um marco da filosofia. Ao invés de morrerem nesta feitoria, saíram de lá e logo adiante encontraram um país inigualável chamado de Utopia, habitada por pessoas singulares no seu modo de vida, os utopianos. Vivem em perfeita harmonia, nada Ihes falta, comida em abundância, mas não comem exageradamente, todos trabalham mas também se divertem. Não dão valor ao que outros povos normalmente prezam muito e para mostrar seu desprezo ao ouro e a prata não são usados como adornos. As jóias são para as crianças se enfeitarem e brincarem, os adultos não se interessam por elas (MAGALHÃES, 2003).

Rosa Magalhães termina seu enredo sugerindo que o Brasil deveria seguir o modelo de Utopia e, assim, preservar o pau-brasil e a mata atlântica.

Vale ressaltar que após escrever o texto que introduz o enredo, a carnavalesca indica a bibliografia consultada para sua construção. As pesquisas que a artista faz para seus enredos são apontadas pela comentarista da Rede Globo Maria Beltrão na transmissão desse carnaval.

Uma das marcas de Rosa Magalhães é escolher enredos que rendem essas longas pesquisas. Ela sempre traz da história fatos curiosos, que pouca gente conhece. Nunca é um tema banal! O enredo da Imperatriz sempre vem revestido de um conteúdo bem original. E isso acaba se transformando em títulos. Já são cinco que a Rosa Magalhães conseguiu para a Imperatriz!

Ao ser indagada sobre a proposta do tema de Rosa Magalhães para o desfile de 2004, a comentarista Maria Augusta ressalta a preocupação com a pesquisa no trabalho da artista: "A Rosa é uma pessoa muito competente! Que faz pesquisas maravilhosas! Às vezes tira água de pedra! E nesse caso é um assunto muito rico! Acredito que vamos ter um belo espetáculo!"

A primeira referência à arte erudita no desfile é implícita. Logo no início, quando o enredo apresenta as bruxas preparando o vermelho em seus caldeirões, aparece uma ala com o nome "Sabá das Bruxas", que tem corujas como elementos presentes nas fantasias. Essas corujas se assemelham, em sua forma, às representadas por Francisco de Goya em suas gravuras. De acordo com Hughes (2007), Goya realizou, no final do século XVIII, uma série de pinturas sobre bruxaria e satanismo, encomendadas pela duquesa de Osuna. Segundo o autor, a duquesa era uma pessoa culta, de pensamento iluminista, mas gostava do teatro popular e dos temas de feitiçaria que povoavam o imagi- 
nário do povo espanhol de então. Entre os quadros encomendados pela duquesa está a obra Aquelarre - Sabbath das Bruxas, título igual ao nome da ala do desfile de Rosa Magalhães: "Os habituais acessórios góticos do horror - morcegos e corujas - batem asas no céu, onde existe, naturalmente, uma lua crescente" (HUGHES, 2007, p. 186). Hughes afirma que em toda a obra de Goya as corujas aparecem como referência à feitiçaria. Em sua série de gravuras em metal intitulada Los caprichos, aparecem as temáticas de bruxas, comédias sexuais, inquisição e o comportamento de monges e padres. A gravura mais famosa da série, El sueño de la razón produce monstruos, contém inúmeras corujas pairando sobre o indivíduo. Nessa obra o artista pretende criticar e combater a superstição do povo espanhol, ideal oposto ao iluminismo, corrente defendida por Goya.

Em visita ao barracão da Imperatriz Leopoldinese no dia 28 de julho de 2010, em companhia do aderecista Sérgio Farias, tentamos localizar o desenho da fantasia mencionada. Não o conseguimos, porém localizamos o desenho de uma fantasia do mesmo setor, que fazia parte do carro abre-alas. No chapéu da fantasia é possível observar a meialua, símbolo herege relacionado às bruxas e presente na obra de Goya, como indicado na citação anterior de Hughes e também presente na próxima citação visual erudita da carnavalesca no desfile, Hieronymus Bosch.

A segunda referência à arte erudita encontrada no desfile "Breazail" é explícita e está presente na segunda alegoria da escola. A referência é mencionada pela comentarista da Rede Globo, Maria Augusta: "Esse carro, o segundo carro da Imperatriz, foi inspirado em Hieronymus Bosch, um pintor europeu que tem uns quadros fantásticos, ele foi um grande surrealista! E que já falava desse processo de alquimia (...)." Nesse momento, quando a carnavalesca reproduz um laboratório de alquimia, temos uma relação direta com a obra $O$ jardim das delícias", de Hieronymus Bosch.

Herbert Read (apud CIVITA, 1977) afirma que, apesar de Bosch viver na aurora do Renascimento, ele é essencialmente um artista do medieval ou do gótico recente. A alquimia, tema que Rosa Magalhães pretende representar, é uma constante na obra de Hieronymus Bosch:

Figura 5: Rosa

Magalhães, projeto para o carro Laboratório de Alquimia, guache sobre papel, 2003

Fonte: barracão da Imperatriz Leopoldinense, 2010.

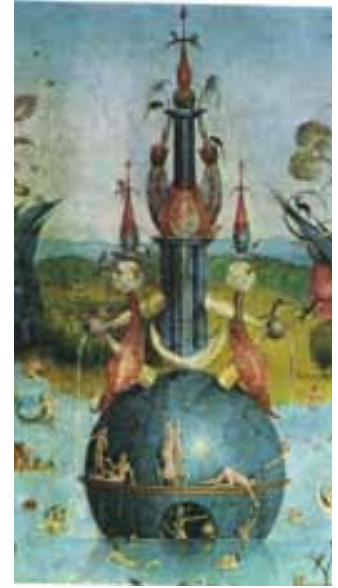

Figura 6: Hieronymus Bosch, detalhe do retábulo central do tríptico $O$ jardim das delícias, óleo sobre madeira, 220 $x 389 \mathrm{~cm}, 1500$ 1505; Museo do Padro, Madri Fonte: Civita, 1977. 
Bosch também utiliza o repertório do gnosticismo alquimista. Pelos arquivos históricos da época não é possível depreender que em sua cidade tenha havido pesquisadores da pedra filosofal e da trasmutação dos metais, mas, de uma maneira ou de outra, aparecem em vários de seus quadros alguns símbolos típicos da alquimia: o ovo (símbolo do conhecimento), a árvore (representação da ascensão) e a sexualização dos elementos (CIVITA, 1977, p. 15).

No carro alegórico desenvolvido por Rosa Magalhães é possível identificar elementos de um laboratório de alquimia com a mescla de elementos sexuais, tão presentes na obra de Bosch. $\mathrm{O}$ aparato laboratorial remete às trompas uterinas, formas orgânicas - assim como a obra do pintor. Também é possível observar na alegoria a repetição dos minaretes estilizados, presentes nos dois primeiros retábulos do tríptico.

As referências ao pintor ficam mais evidentes se observarmos os projetos da carnavalesca para a concretização da alegoria que conseguimos no barracão da Imperatriz Leopoldinense por intermédio de Sérgio Farias.

$\mathrm{Na}$ Figura 5 percebemos a releitura que a carnavalesca faz da parte central do tríptico de Bosch (Figura 6). Rosa Magalhães se aproxima da forma ornamental desse "minarete", mantendo a coluna azul do artista, feita aparentemente em mármore. A meia-lua está presente em ambas as situações - na alegoria de Rosa e na obra de Bosch. Outras formas são simplificadas no projeto da artista, mas a silhueta desse elemento cenográfico permanece. Essa referida cenografia é outro elo entre os dois artistas.

O século XV assistiu a uma expansão notável dessas formas teatrais, que eram enriquecidas com a agregação contínua de novos episódios e com a complexidade crescente de sua coreografia e cenografia. A Confraria de Nossa Senhora (a que pertenceu o pintor) subvencionava esses espetáculos e Bosch estava sempre ligado a eles (CIVITA, 1977, p. 15).

Vale citar que a alegoria de Rosa Magalhães era toda coreografada. Atores vinham trajados como trabalhadores e alquimistas desse laboratório e utilizavam os elementos cênicos propostos pela carnavalesca.

O próximo projeto da artista (Figura 7) dialoga com o minarete rosa presente no primeiro retábulo de Bosch (Figura 8). Ela se apropria apenas da parte inferior do elemento e elimina o círculo central em que uma coruja está inserida. A coruja aparece no desfile na fantasia mencionada anteriormente e também é constante, como verificado, na obra de Goya, em que a temática de bruxaria é frequente.

Civita (1977) se refere aos símbolos uterinos, fálicos e coitos na obra do pintor flamengo. No último retábulo do tríptico, observa-se elemento que remete tanto ao sexo feminino, representado pelo ovário, quanto aos utensílios de um laboratório de alquimia (Figura 9). Rosa Magalhães inclui esse objeto em sua alegoria, como verificado no projeto (Figura 10).

A última referência visual de arte erudita compreendida por este trabalho também pode ser relacionada com a organicidade e o aspecto onírico de Bosch. A referência está no último carro alegórico da escola e é assim apresentada por Cléber Machado na transmissão do desfile: "Atrás do carro vocês vão ter a oportunidade de ver uma re- 
Figura 7: Rosa Magalhães, projeto para o carro Laboratório de Alquimia, guache sobre papel, 2003

Fonte: barracão da Imperatriz Leopoldinense, 2010.

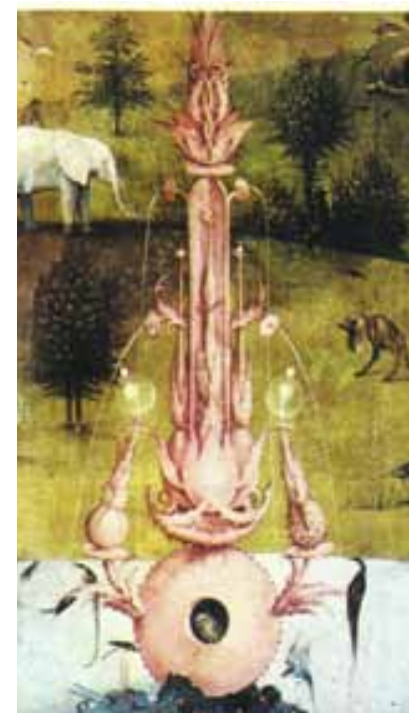

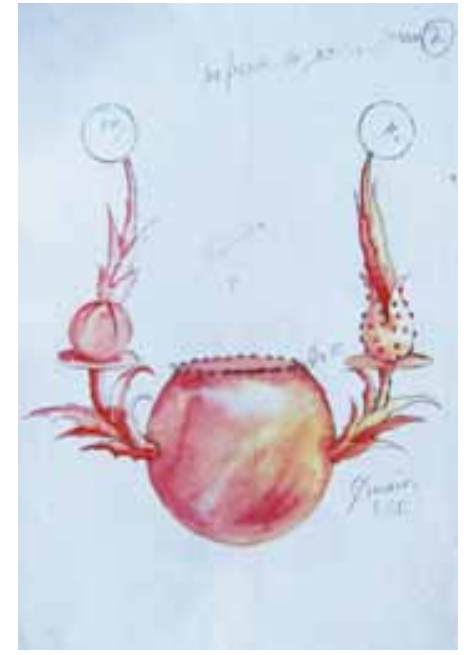

Figura 8: Hieronymus Bosch, detalhe do primeiro retábulo do tríptico 0 jardim das delícias, óleo sobre madeira, 220 x 389cm, 1500-1505, Museo do Prado, Madri

Fonte: Civita, 1977.

produção do Parque Guell, que é um parque do Gaudí que tem lá em Barcelona, na Espanha, onde viveu o Gaudí, um grande artista!" A comentarista Maria Augusta complementa a fala de Machado:

Olha! A Rosa mais uma vez foi muito feliz nesse final de Imperatriz. Essa inspiração no Gaudí, que foi um arquiteto espanhol fantástico! Diferente de tudo que já houve. Ele é um arquiteto próximo ao Surrealismo, há divergências. Mas esse detalhamento! Carro de cerâmica! Carro de azulejo! Coloridos! Isso é típico da arquitetura de Gaudí. E essas curvas - não há retas na arquitetura - sempre uma coisa muito orgânica, muito gordinha! Essa coisa do latino. Formas latinas, formas orgânicas - da natureza - que ele levava para as suas obras em Barcelona, obras inesquecíveis!

O referido carro dialoga, como mencionado, com aspectos da arquitetura de Gaudí e representa Utopia, de Thomas More. Na Figura 11 é possível observar a organicidade das formas mencionada por Maria Augusta.

As referências ao arquiteto ficam mais explicitas se observarmos os projetos da carnavalesca para o carro A Utopia (imagens 12, 13, 15 e 17). Percebe-se que Rosa Magalhães não se limita a citar apenas uma obra do arquiteto. Ela utiliza, além do Parque Guell, elementos presentes nas chaminés da Casa Battló (imagem 16) e nas torres da Igreja da Sagrada Família (imagem 18), ambas as construções localizadas em Barcelona. Vale observar aqui que todas as obras eruditas referenciadas pela artista neste desfile possuem algo em comum: situam-se em território espanhol. 
Figura 9: Hieronymus Bosch, detalhe do terceiro retábulo do tríptico $O$ jardim das delícias, óleo sobre madeira, 220 x 389cm, 1500-1505, Museo do Prado, Madri Fonte: Civita, 1977.
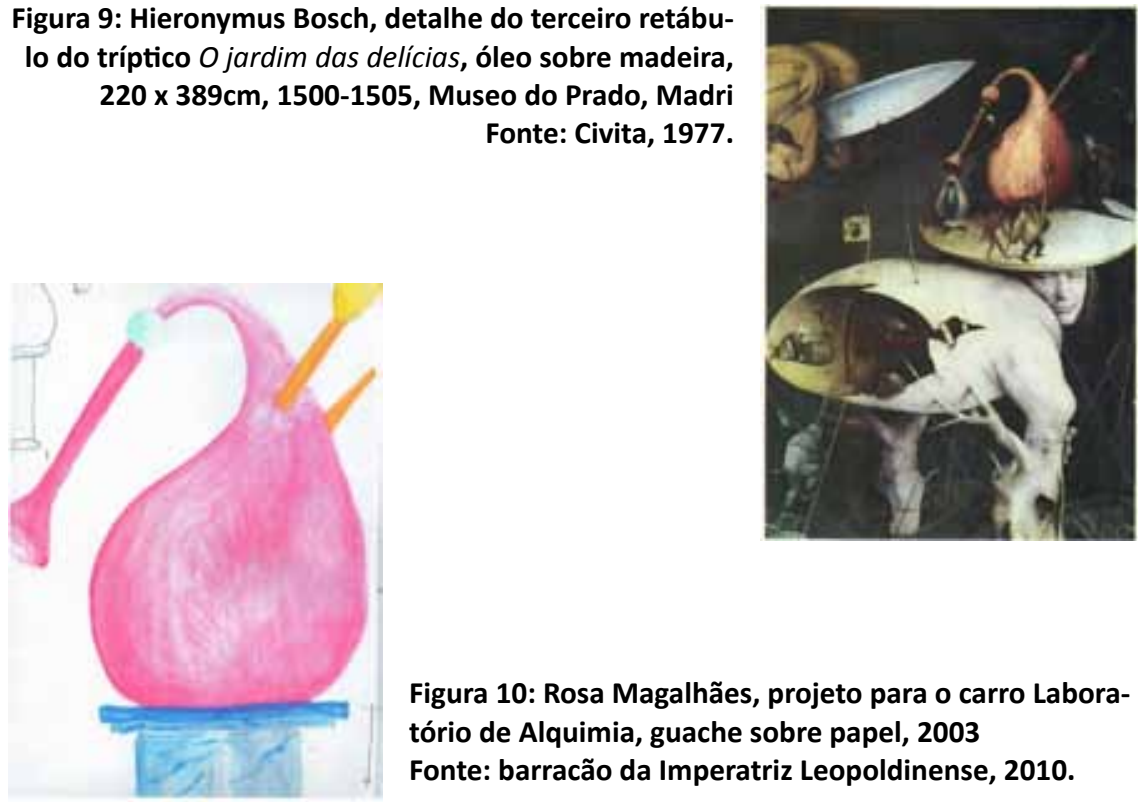

Figura 10: Rosa Magalhães, projeto para o carro Laboratório de Alquimia, guache sobre papel, 2003 Fonte: barracão da Imperatriz Leopoldinense, 2010.

Nos projetos da carnavalesca percebemos o realce da cor. Os mosaicos feitos para o desfile ganham tonalidade cítrica, se comparados com as construções do arquiteto catalão, sofrendo processo de carnavalização por meio da cor.

O comentarista da Rede Globo Haroldo Costa compara as obras de Gaudí com as do artista popular brasileiro Gabriel Joaquim dos Santos, que fez a construção da Casa da Flor (Figura 19) também utilizando o mosaico e as formas orgânicas em São Pedro da Aldeia (RJ). De acordo com Costa, esse artista popular nunca teve contato com as obras de Gaudí. Aí percebemos um diálogo entre o erudito e o popular que minimiza as polarizações, pois algo parecido foi feito em universos distintos.

Vale ressaltar que as referências à arte erudita no trabalho de Rosa Magalhães não se encerram no desfile analisado; elas estão presentes de diversas maneiras ao longo de sua trajetória profissional.

\section{CONSIDERAÇÕES FINAIS}

De norte a sul de nosso território comemoramos o carnaval das mais variadas formas, cada região com sua peculiaridade. É na cidade do Rio de Janeiro, contudo, que acontecem os desfiles das escolas de samba do Grupo Especial, uma das mais potentes manifestações culturais do planeta, capaz de integrar olhares populares e eruditos. Aproximadamente quatro mil pessoas em cada uma das 12 escolas, vindas de favelas ou mansões, de cidades brasileiras ou mesmo do exterior, com contagiante alegria cantam e dançam um samba-enredo que provém de uma bateria furiosa em que ritmistas não poupam esforços para fazer soarem suas caixas, chocalhos, cuícas, surdos de marcação, 
pandeiros e outros instrumentos que reproduzem aquele "bumbum paticumbum prugurundum" em cadência impecável.

Além de dançar e cantar, trajam fantasias que são uma sobreposição de diversos materiais, cores e referências, indicando a personagem ou assunto do enredo. Há ainda os carros alegóricos, que são palcos de ópera ambulantes, recheados de esculturas, luzes, brilhos e fantasias; alguns são preciosos nos detalhes, como jóias. Os carros alegóricos são os cenários habitados pelos integrantes das escolas na hora do desfile para contar uma história por meio do enredo.

Quem idealiza fantasias, cenários e histórias é o carnavalesco, uma profissão bem brasileira. Magalhães (1997) compreende esse sujeito como uma espécie de diretor de cena. É o indivíduo responsável pela parte visual de um desfile de escola de samba. Em alguns casos, de acordo com a autora, o carnavalesco também faz o enredo, porém, algumas vezes, a própria diretoria da escola pode escolher o tema para que o artista desenvolva em forma de desfile. Magalhães aponta que muitos carnavalescos são autodidatas e intuitivos, porém há outra parcela que é composta por artistas graduados em algum curso de belas artes.

A citação que segue aponta as funções exercidas pelo carnavalesco em uma escola de samba.

A rotina de trabalho segue mais ou menos o mesmo caminho ano a ano. Primeiro faz-se o enredo, que é distribuído para os compositores (que farão o

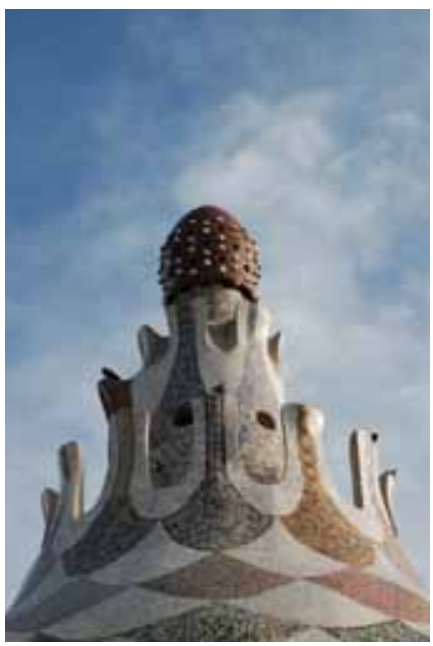

\section{Figura 11: Antoni Gaudí, Park Guell, Barcelona, 1900-1914 \\ Fotografia do autor.}

Figura 12: Rosa Magalhães, projeto para o carro A Utopia, guache sobre papel, 2003 Fonte: barracão da Imperatriz Leopoldinense, 2010. 


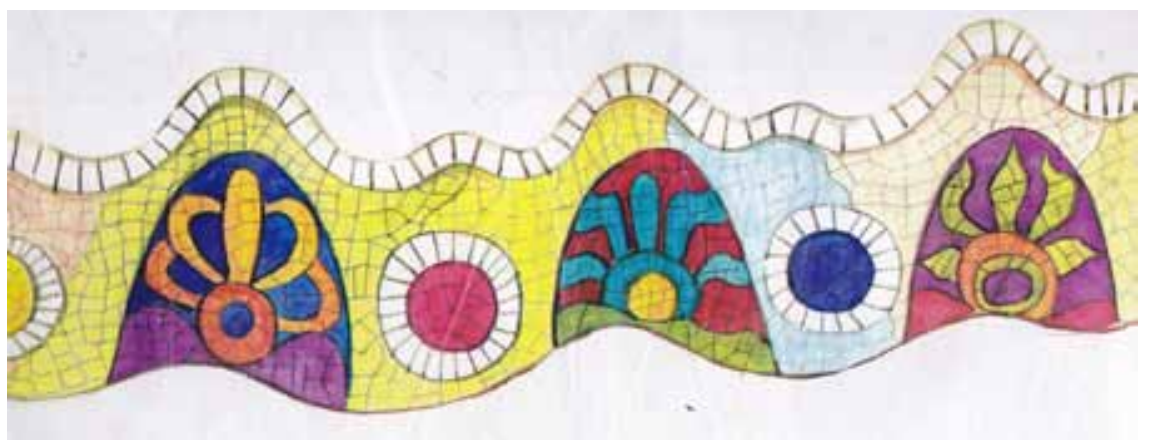

Figura 13: Rosa Magalhães, projeto para o carro A Utopia, guache sobre papel, 2003 Fonte: barracão da Imperatriz Leopoldinense, 2010.

samba da escola). Em seguida, desenham-se as fantasias e os carros alegóricos. Em primeiro lugar, executam-se trajes piloto para que possam ser multiplicados em tempo hábil (...) Após ter feito o projeto, o carnavalesco tem a chance de ver funcionando os vários setores, e se torna uma espécie de mestre de obras que acompanha a realização de suas ideias. (MAGALHÃES, 1997, p. 135)

No grupo de carnavalescos do Rio de Janeiro está Rosa Magalhães. Com formação acadêmica sólida, ela imprimiu um jeito particular e respeitado de fazer desfile de carnaval. Seus trabalhos como carnavalesca, apontados neste artigo, são repletos de referências pertinentes às mais variadas áreas. A qualidade da obra de Rosa Magalhães resultou em muitos prêmios no campo da arte, alguns de relevância internacional.

A inserção de elementos da arte erudita na festa popular é uma das características mais marcantes do trabalho da carnavalesca. O folião, que desfila em um cortejo desenvolvido pela artista, pode carregar referências de Francisco de Goya em sua indumentária. Esteja ele consciente desse diálogo ou não, há uma releitura presente, mesmo que de forma implícita. Esse mesmo folião é inserido ainda em um cenário inspirado em Hieronymus Bosch. Há aí a integração de dois universos que talvez não possuíssem integração. De um lado temos o sambista popular, o desfilante, que pode ou não compreender

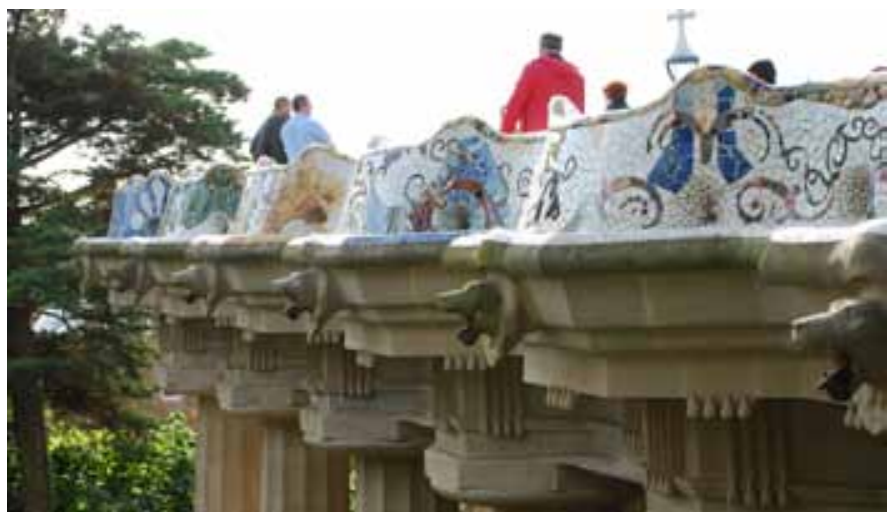

Figura 14: Antoni Gaudí, bancos do Park Guell, Barcelona, 1900-1914 Fotografia do autor. 


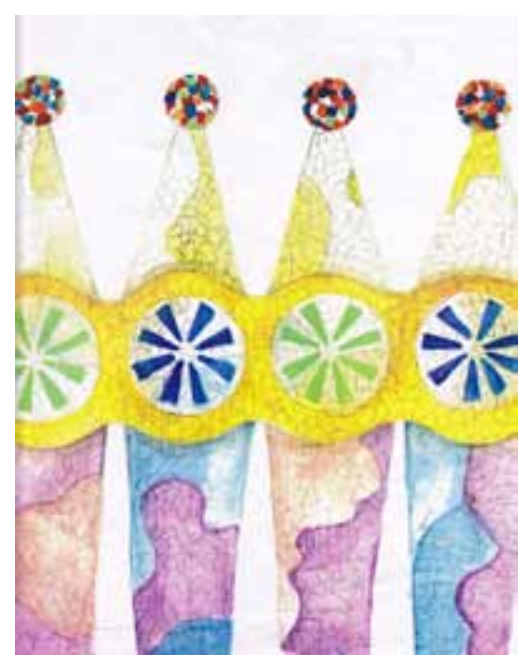

Figura 16: Antoni Gaudí, chaminés da Casa Battló, Barcelona, 1904-1906 Fotografia do autor.
Figura 15: Rosa Magalhães, projeto para o carro A Utopia, guache sobre papel, 2003 Fonte: barracão da Imperatriz Leopoldinense, 2010.

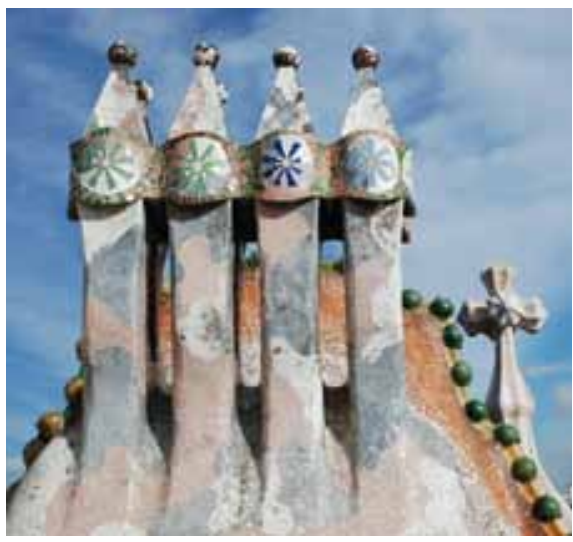

o outro lado, o das referências visuais eruditas. O mesmo acontece com o público que assiste aos desfiles, seja no sambódromo, seja em casa, em suas televisões.

Por meio do caso Rosa Magalhães, observamos a materialização do conceito de circularidade tratado por Ginzburg (1987). Em festa popular, um desfile das escolas de samba do Rio de Janeiro, emergem referências e diálogos possíveis com a arte erudita e com o público que é entendedor e conhecedor de arte. $O$ erudito e o popular acabam integrando-se, mas essa integração só ocorre com a proposição da artista, que "expõe" esses artistas fora dos espaços dos museus.

A hibridação concretiza-se quando o público leigo, via os meios de comunicação de massa, tem a oportunidade de apreciar as citações artísticas eruditas do mundo da arte num desfile de carnaval. Neste trabalho foram utilizados muitos comentários retirados das transmissões da Rede Globo. Por mais superficiais que se configurem, fazem a mediação necessária para o público leigo compreender a referência que origina tais formas e cores, e assim se estabelece um pouco da horizontalidade comunicacional defendida por Canclini (2000).

Tendo em mente a obra de Rosa Magalhães, idealizadora de ímpar universo visual, o desfile de carnaval se desvela a nós como uma manifestação cultural e artística de inúmeras possibilidades no que se refere à visualidade. Como artista plástica que é, Rosa Magalhães possui a capacidade de englobar e se apropriar de várias linguagens, alimentando-se das referências do mundo da arte e renovando seu repertório a cada ano. 
Figura 17: Rosa Magalhães, projeto para o carro A Utopia, guache sobre papel,

2003

Fonte: barracão

da Imperatriz Leopoldinense, 2010.
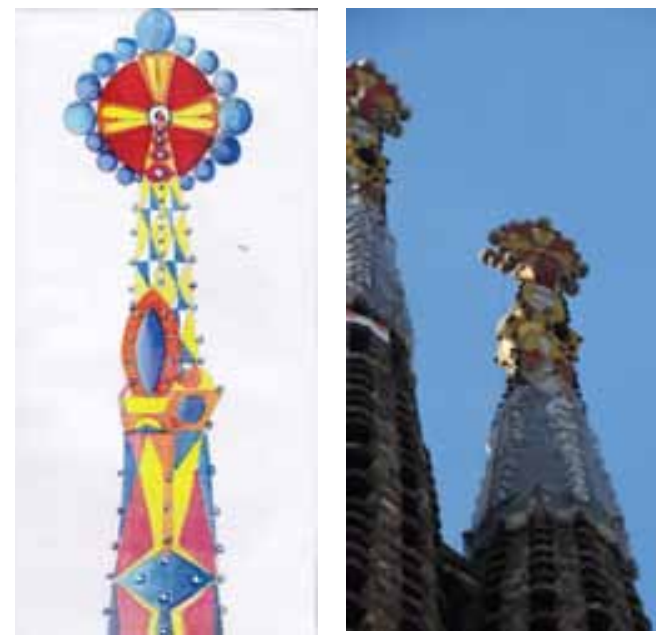

Figura 18: Antoni Gaudí, Templo Expiatório da Sagrada Família, Barcelona, 18831926 Fotografia do autor.

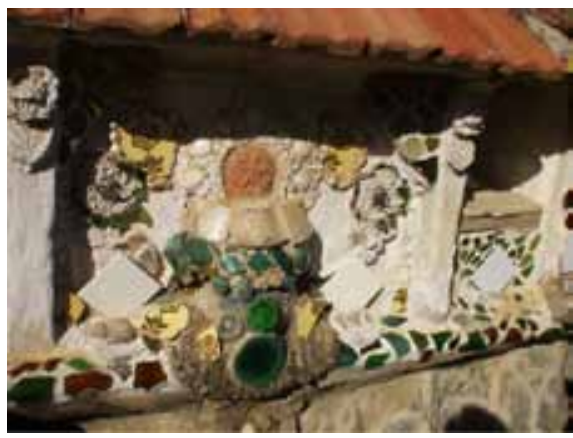

Figura 19: Gabriel Joaquim dos Santos, Casa da Flor, São Pedro da Aldeia, 19231985 Fonte: Mosaicos do Brasil.

O desfile de carnaval, assim como a ópera, exige entendimento capaz de relacionar performance, música, escultura, pintura, desenho, teatro, literatura e dança - a busca da obra de arte completa e total, defendida por Goethe e perseguida por Richard Wagner (PARRONDO, 2008). Na costura e nas sobreposições de elementos populares e eruditos, a artista contribui para o movimento de circularidade e fomenta a hibridação no processo cultural, integrando os universos dos museus, das festas populares e da cultura de massa.

\section{REFERÊNCIAS BIBLIOGRÁFICAS}

ANTHOLOGY of art. Disponível em: www.anthology-of-art.net/generatio/02/vare.html. Acesso em: 24/10/2010.

BAKHTIN, M. M. A cultura popular na Idade Média e no Renascimento: o contexto de François Rabelais. Brasília: Editora da Universidade Federal de Brasília, 1993.

CANCLINI, Néstor García. Culturas híbridas: estratégias para entrar e sair da modernidade. 3. ed. São Paulo: Editora da Universidade de São Paulo, 2000.

CIVITA, V. Hieronymus Bosch. São Paulo: Editora Abril, 1977.

FERREIRA, Felipe. O marquês e o jegue: estudo da fantasia para escolas de samba. Rio de Janeiro: Altos da Glória, 1999. 
GINZBURG, C. O queijo e os vermes: o cotidiano e as ideias de um moleiro perseguido pela inquisição. São Paulo: Companhia das Letras, 1987.

HUGHES, Robert. Goya. São Paulo: Companhia das Letras, 2007.

MAGALHÃES, Rosa. Fazendo Carnaval/The Making of Carnival. Rio de Janeiro: Nova Aguilar, 1997.

Sinopse do enredo Imperatriz Leopoldinese 2004. Rio de Janeiro, 2003.

. Sinopse do enredo Imperatriz Leopoldinese 2007. Rio de Janeiro, 2006.

MOSAICOS do Brasil. Disponível em: mosaicosdobrasil.tripod.com/id11.html. Acesso em: 27/08/2010.

PARRONDO, J. C. Picasso. La Danza [De Le Tricorne a las Suites 347 Y 156]. Madri: Fundación Bancaja, 2008.

SIDNEY Rezende Carnavalesco. Disponível em: www.sidneyrezende.com/noticia/61567. Acesso em: 20/11/2009.

Dulce Regina Baggio Osinski é artista plástica, ilustradora e pesquisadora de arte formada pela Escola de Música e Belas Artes do Paraná, com pós-graduação na Academia de Belas Artes de Cracóvia, Polônia, e aperfeiçoamento em arte-educação na Universidade do Tennessee em Chattanooga, EUA. É mestre e doutora em educação pela UFPR, atuando como docente e orientadora no curso de Licenciatura e Bacharelado em Artes Visuais e no Programa de Pós-graduação em Educação daquela instituição.

Gustavo Krelling iniciou seus estudos de graduação no curso de Indumentária da UFRJ. É formado em educação artística - habilitação em artes plásticas - pela UFPR e em jornalismo pela Universidade Positivo. 